\title{
ENTRE A FILOSOFIA E O DIREITO: UMA ABERTURA AO CAMPO DAS SENSAÇÕES COMO FUNDAMENTO DA ESTÉTICA DO DIREITO
}

\author{
Joaquim Cerqueira Neto ${ }^{1}$
}

\section{Resumo:}

O presente trabalho propõe uma reflexão acerca do Direito a partir de seu ponto de interseção com a Filosofia. Esse ponto comum entre a Filosofia e o Direito seria o campo das sensações. Para tanto, adota o método genético de pesquisa, ao propor uma aproximação entre o conceito de não filosofia em Deleuze-Guatarri e o conceito de amor como idoneidade original do Direito em Francesco Carnelutti, produzindo, assim, uma chave de leitura imanente do fenômeno jurídico e de sua índole emancipadora, plural e democrática, já que fundado no campo das sensações, afirmando-se simultaneamente como expressão ética e estética do real.

Palavras-chave: Filosofia; Direito; Campos das Sensações; Estética do Direito; Amor.

\section{BETWEEN PHILOSOPHY AND LAW: AN OPENING TO THE FIELD OF SENSATIONS AS THE FOUNDATION OF THE AESTHETICS OF LAW}

\begin{abstract}
:
The present work proposes a reflection on Law from its point of intersection with Philosophy. This common point between Philosophy and Law would be the field of sensations. To do so, it adopts the genetic method of research, by proposing an approximation between DeleuzeGuatarri's concept of non-philosophy and Francesco Carnelutti's concept of love as the original suitability of Law, thus producing an immanent reading key of the legal phenomenon and of its emancipating, plural and democratic nature, since it is founded on the field of sensations, simultaneously asserting itself as an ethical and aesthetic expression of the real.
\end{abstract}

Keywords: Philosophy; Law; Fields of Sensations; Aesthetics of Law; Love.

\section{INTRODUÇÃO}

O presente trabalho é resultado de pesquisa. Vale mencionar que nasceu de indagações múltiplas acerca do que é o direito e como ele pode ser instrumento de emancipação humana. Indagava-se sobre sua potencialidade para a efetivação da justiça. A questão proposta foi buscar uma releitura imanente do Direito, ou seja, algo presente ou interno ao fenômeno jurídico.

Para tanto, partiu-se da análise da ideia da Não Filosofia apresentada por Gilles Deleuze e Felix Guattari (1992), para os quais a filosofia não pode contentar-se em ser

\footnotetext{
${ }^{1}$ Mestre em Ciências Sociais pela Pontifícia Universidade Católica do Rio de Janeiro (PUC-Rio). Docente do Curso de Direito da Universidade Estácio de Sá - UNESA. E-mail: joaquimcneto@gmail.com. Currículo na plataforma Lattes http://lattes.cnpq.br/3771354357421059
} 
compreendida apenas a partir do campo conceitual, embora sua matéria-prima seja o conceito, pois existe algo que está na sua base, constituindo fundamentalmente suas condições internas.

Assim, encontra-se presente um plano de imanência na essência da própria filosofia, revelando que, antes de ser conceito, ela é um movimento múltiplo, dinâmico e incessante, sem que nada exista fora dela.

Em seguida, sentimos nascer a inquietação para se pensar um Não Direito, isto é, apontamos para o campo das sensações no Direito, enquanto origem ou gênese comum à Filosofia e ao Direito. Com outras palavras, passamos a pensar o Direito a partir do campo das sensações, enquanto aquele que se constitui através das diversas atividades humanas, seja na literatura, música, dança, escultura, arquitetura, pintura etc.

Entendendo-se a arte como a capacidade humana para a livre criação, tem-se no Direito essa expressão artística a partir da qual o homem organiza sua vida em sociedade. Eis aí a compreensão do Direito como criação do homem na história (Cunha, 1998), expressividade pulsante e criação do novo, puro devir.

Segundo Francesco Carnelutti (2005), o que une o povo ao Estado é uma força chamada direito. Essa força figura-se como uma armação que dá consistência à construção desse arco (ou ponte), unindo cada tijolo ao todo. Na sua perspectiva, um Estado perfeito não necessitaria mais de um direito, embora este possua uma força capaz de mudar o mundo. Com outras palavras, para ele, o Direito possui um poder de transformação denominado idoneidade, que possui sua verdadeira potência original no seu âmago, ou seja, sua idoneidade original seria o Amor.

Com efeito, adotou-se a perspectiva do método genético de pesquisa, considerando-se o Não Direito enquanto força imanente do próprio Direito, construída a partir do campo das sensações, da experiência humana do viver e do conviver, do sentir o mundo real, na relação do "eu" com o "outro", para daí fazer nascer o "nós". O que se pretende, em suma, é sublinhar como o Direito detém em essência essa potencialidade humana de organizar e transformar a realidade, ou seja, projeta-se enquanto potência de construção múltipla, emancipadora e democrática do real.

\section{DA ESTÉTICA: A ARTE COMO EXPRESSÃO DA SENSIBILIDADE HUMANA}

"Mais sei de uma coisa: meu caminho não sou eu, é outro, é os outros.

Quando eu puder sentir plenamente o outro 
estarei salva e pensarei: eis o meu ponto de chegada".

(Em Busca do Outro. A Descoberta do Mundo. Clarice Lispector. 1999, p.119)

Dentre os vários aspectos que diferenciam os homens dos animais, podemos apontar a linguagem como um fator particular da essencialidade humana. Ainda que os animais emitam sons e sinais comportamentais para estabelecer uma comunicação, somente o homem se comunica através da palavra, escrita ou falada, o que torna a linguagem humana um fator decisivo para a diferenciação e criação do universo cultural humano.

Conforme nos faz lembrar Daury César Fabriz,

a diferença entre a forma de comunicação animal e do homem reside no conhecimento dos símbolos e dos signos. Desse modo, o processo de humanização ocorre com o convívio entre os seres humanos, que nos remete ao mundo dos símbolos, através da aprendizagem da linguagem”. (Fabriz, 1999, p.31)

Assim, é através da linguagem que o homem é capaz de criar a sua própria realidade. Isto porque a linguagem permite uma maneira efetiva de expressão da experiência concreta, abrindo a possibilidade de organização e reorganização daquela realidade na qual se encontra inserido. Com efeito, importa dizer que esta construção acontecerá numa dimensão sensível, vez que ela ocorre no plano das relações sensíveis para, em seguida, passar ao plano do simbólico e, enfim, da concretude, momento no qual se aplica, interfere e transforma essa mesma realidade objetiva a partir de suas necessidades.

Pelo exposto, já é possível perceber que "enquanto o animal permanece em seu estado natural, o homem, através de sua capacidade de pensar e racionar, com base na simbologia de sua linguagem, é capaz de transformar a natureza que o cerca, possibilitando o surgimento da cultura" (Fabriz, 1999, p. 32).

Com essas palavras, o autor visa exprimir essa natureza cultural do universo humano, na medida em que a realidade está em constante processo de transformação.

Vivendo em sociedade, o homem interpreta a sua realidade e transfere sua interpretação ao outro, transmitindo assim valores, sentidos e significados de sua própria existência. Eis aí a forma pela qual ele pensa, sente e age na sua sociedade, na sua cidade, com um determinado jeito, por meio de uma língua, inúmeros objetos etc, enfim, quando ele produz cultura. Nos ensina o autor, ao afirmar que "o homem, através da simbolização, tematiza o mundo segundo determinadas características, tornando-o uma realidade 
compreensível. É a partir dessa capacidade de pensar através de símbolos que reside sua humanidade. Enfim, o homem é um ser cultural” (Fabriz, 1999, p.32).

Pode-se concluir daí que o modo de ser de uma sociedade está estreitamente ligado à criação de signos e valores por cada um de seus membros, visando justamente transformar e moldar a realidade de acordo com as necessidades.

Por conseguinte, a cultura se apresenta como expressão da ação humana na realidade concreta. Nesse passo, esta realidade cultural é fruto de um processo histórico e social que está na base da formação desta mesma sociedade. Realidade cultural, história, sociedade, consistem em produtos da ação humano no tempo e espaço. Em uma palavra: puro devir.

No âmbito do direito, é válido assinalar que ele

somente pode ser compreendido quando visualizado como objeto da cultura, elaborado pelo espírito do homem, a fim de sanar suas necessidades no contexto social, tornando sua vida possível e, por assim ser, não há como afastá-lo de sua dimensão axiológica (Fabriz, 1999, p.35)

O elemento valorativo ou axiológico vai surgir com toda sua potência para indicar que toda criação humana está pautada por uma necessidade, e mais do que isso, é portadora de sentidos e significados, não parando de se movimentar e não se esgotando no indivíduo, mas permeando as atividades humanas. Por isso, considerada um produto cultural, fundado na diversidade enquanto causa necessária e imanente da realidade social e humana.

É no campo do valor onde podemos perceber a atividade humana de construção do seu mundo real a partir do seu aspecto subjetivo, ou seja, a potencialidade humana de que somos portadores. O tecido social é constituído por vários indivíduos, o que nos permite admitir uma multiplicidade, uma coletividade humana produzindo os canais de sua sobrevivência. Assim, antes de dizermos qualquer coisa perto da morte da estética, estamos, antes, demonstrando que seu acontecimento é inevitável e efetivamente infinito.

À guisa de advertência, não procuremos fazer uma abordagem aprofundada acerca da dimensão conceitual sobre a estética e de seus períodos históricos, mas apenas destacar os pontos mais relevantes que instigaram o estudo sobre o que é a beleza, e como a questão do belo foi se aproximando à noção de arte. Entretanto, como ficará claro ao final do presente estudo, a concepção de arte tomada por nós não está meramente ligada à noção do que é bom e belo, concepção estabelecida entre os autores doravante citados, mas ressaltar que a dimensão estética tanto no direito quanto na filosofia está relacionada à capacidade radical de criação do ser humano e de sua afirmação através da experiência do sentir. 
Sabemos que o termo estética remonta ao grego aisthesis, que vem da raiz verbal grega "aisth", formando o verbo "aisthánomai", o que conduz à ideia do sentir através da rede de percepções físicas, que ganham sentido a partir do campo das sensações e percepções humanas. É esta estética do Belo que nos remete também à estética do Justo, ou seja, do encontro com a Justiça.

Na realidade, o termo estética aparecerá por volta de 1750 com o trabalho do filósofo alemão Alexander Baumgarten, o qual buscava designar uma nova disciplina da filosofia, filosofia da arte, ao cuidar da compreensão e dos significados suscitados ao homem pelo belo.

Conforme salienta Denis Huisman,

Num primeiro sentido - que é, aliás, o seu senso primário - a filosofia da arte designa originalmente a sensibilidade (etimologicamente aisthésis significa, em grego, sensibilidade) com a dupla acepção de conhecimento sensível (percepção) e aspecto sensível de nossa afetividade. Num segundo sentido, bem mais atual, ela designa toda reflexão filosófica sobre a arte. Isto significa que o objeto e o método da estética dependerão da maneira de definirmos a arte. Em seguida, poderemos tratar da psicologia do homem diante da arte ou da sociologia do homem em presença da beleza. (Fabriz, 1999, p.7)

$\mathrm{Na}$ verdade, Baumgarten inseriu a estética no debate científico do séc. XVIII pretendendo investigar as condições de possibilidade e os limites da experiência de prazer relativo ao belo. A esse momento da história da estética Denis Huisman ${ }^{2}$ chama de "idade positiva" ou técnica.

Todavia, a questão é que o sentimento causado pelo belo, pela sensibilidade artística, não começa no século XVIII. Ocorre aí apenas o seu contorno científico, na busca de transformar a arte em ciência. Ou seja, ocorre uma redução do sentir, das sensações, conforme destaca Cunha (1998, p. 133). Ocorre que as investigações acerca do belo e da arte já vinham sendo realizadas desde a antiguidade quando, em 1750, a estética se constitui como disciplina autônoma no sistema das ciências, ou seja, com método, objeto de estudo e conceito próprios (Cunha, 1998; Fabriz, 1999).

A temática da estética aparece no século XVIII, mas a base de tal reflexão encontra-se na Grécia, no pensamento de três grandes filósofos: Sócrates, Platão e Aristóteles.

\footnotetext{
${ }^{2}$ Segundo ele, podemos distinguir em três fases a história da estética: a idade dogmática, a idade crítica e a idade positiva.
} 
Para Sócrates (470-399 a.C) a questão do belo estaria na beleza em si mesma, o que impediria que ela fosse reduzida ou determinada por apenas um único objeto ou única forma humana. A beleza seria algo universal da qual participariam todas as coisas.

Ao passo que, para seu discípulo, Platão (508-348/347 a.C), haveria uma ideia da beleza suprema, não mais presente em todas as coisas, mas definida por uma ideia primeira do belo. Como salienta Fabriz,

para o pensamento platônico deve haver uma primeira beleza de onde emana a beleza de todas as outras coisas. A beleza torna-se ideia essencial. Apesar do seu caráter sensível, a beleza é objetivamente e essencialmente ideia. $\mathrm{O}$ belo existe em si mesmo tendo um caráter universal; ponto de referência para as obras individuais (Fabriz, 1999, p. 63).

Por fim, é com a perspectiva do belo em Aristóteles (387-322 a.C) que ocorrerá uma significativa e profunda mudança, pois o belo passa ser visto e considerado como um bem, e, enquanto tal, consistirá numa finalidade a ser alcançada pelas ações humanas.

Um outro aspecto dessa mudança diz respeito à caracterização do belo, não mais presente em todas as coisas, como em Sócrates, e também não mais no campo das ideias transcendentes ao mundo humano e sensível, como em Platão, mas sim compreendida a partir de uma perspectiva imanente, já que o homem é capaz de compreender racionalmente o mundo a sua volta, e pode assim instaurar uma harmonia do mundo sensível. Daí "a arte como uma faculdade ligada ao produzir, guiada pela razão verdadeira” (Fabriz, 1999, p65)

Com efeito, o conceito de estética está intimamente vinculado à dimensão do sentir no mundo. Conforme pondera o autor,

do grego aisthesis, vem a significar a faculdade de apreender e compreender pelos sentidos. Podemos dizer que as dimensões da beleza encontram-se vinculadas à nossa percepção em relação a tudo aquilo que nos cerca e com os quais nos relacionamos (Fabriz, 1999, p.63).

Dentre vários posicionamentos acerca do tema da estética, os quais se verificarão a partir da modernidade, selecionamos a perspectiva desenvolvida por Friedrich Nietzsche, pois é aquela que trata da questão da arte e da beleza como um instinto humano para viver. Com outras palavras,

a beleza em Nietzsche encontra-se intimamente ligada à questão dos instintos de potência e impotência. Em busca de se tornar potência, o homem constrói um mundo à sua imagem e, em contato com aquilo que é obra de suas mãos, é tomado por um forte impulso estético, dimensionado à beleza de sua existência (Fabriz, 1999, p.70). 
De certa forma, devemos reconhecer que a arte, nas suas mais variadas formas, na literatura, na pintura, na escultura, na dança, na música, ou no teatro, como exemplos, causam em nós uma sensação que está muito ligada ao gosto, ao campo da subjetividade do indivíduo que exterioriza seus desejos e vontades.

Contudo, deve-se enfatizar que a experiência estética está para além dessa manifestação da arte e do belo, significando radicalmente uma vontade humana que parte de sua capacidade para a criação e significação do mundo. Caso contrário, teremos que admitir que a experiência estética fique associada ao domínio da aparência em contraposição ao essencial. É bem verdade que esse mundo da aparência foi colocado de lado por dizer respeito ao mundo sensível, enquanto a essência seria o mundo inteligível. Durante toda a história do pensamento filosófico temos esta questão determinada. Porém, já encontramos uma base sólida para enfrentá-la aqui, bem como aquelas questões anteriormente formuladas.

Por consequência, há um problema ao se desvalorizar o mundo sensível, pois ao se atribuir a ele o inconveniente do erro devido às emoções e paixões, não podemos negar que é sobre ele que meu campo perceptivo atua. Obviamente, a noção de sensível estaria para além das aparências e dos sentimentalismos, ou seja, guarda relação com o duplo aspecto da estética: percepção e afetividade. Através das experiências sensoriais perceptivas, é possível se estabelecer objetivamente uma comunicação com o mundo, enquanto por meio da afetividade tal relação ocorre subjetivamente.

Com relação à possibilidade de erigirmos um princípio que tenha como finalidade a pessoa humana, tudo vai depender do valor que esta possui para uma dada sociedade, assim como seria com relação ao valor liberdade. Esses valores estão compreendidos dentro de escalas de interesses, o que importa dizer que são relativos. Quanto ao mundo sensível, ao campo das sensações, à sensibilidade, não. Todos nós podemos sentir. Acontece é que nossas vidas se encontram orientadas por um racionalismo que põe de lado o próprio ser humano, enquanto pessoa e valor. Assim, não há como construir uma sociedade que tenha como valor supremo a pessoa humana. É preciso criação, mas sequer somos capazes de trocas afetividades verdadeiras em nossas vidas atualmente. Onde então encontraremos esta fonte da sensibilidade? Na arte. Somente através dela podemos restabelecer nossa humanidade, ou melhor, tornar viva a humanidade dentro de nós, sendo o indivíduo artífice do seu destino e a sociedade protagonista da história.

\section{DA NÃO FILOSOFIA: O SENTIR COMO POTÊNCIA PARA A CRIAÇÃo}


“Certamente, filosofia e arte não expressam o pensamento com os mesmos meios. Porém, ambas podem participar de um mesmo plano de pensamento, expressando-o, cada uma, com os meios que lhe são próprios, imanentes"

(Elton Luiz Leite de Souza. Manoel de Barros: a poética do deslimite. 2010, p. 19)

Antes de tudo mais, o primeiro passo a ser dado, no nosso entender, é buscar o significado da palavra Filosofia, bem como seu registro inaugural na história do pensamento ocidental, na medida em que serve para demarcar um ponto de partida importante na sequência de nosso trabalho.

De acordo com os apontamentos da filósofa Marilena Chauí, a palavra Filosofia é de origem grega, sendo composta pela união de duas outras: philo e sophia. Philo deriva da palavra philia, que significa amizade, amor fraterno, respeito entre os iguais. Sophia quer dizer sabedoria e dela vem a palavra sophos, sábio. Nesse sentido, Filosofia significa amizade pela sabedoria, amor e respeito pelo saber, sendo filósofo aquele amigo ou amante da sabedoria, aquele que sempre quer saber, que deseja saber (Chauí, 1995, p.25).

Já em relação ao seu nascimento, alguns estudiosos e historiadores da filosofia dizem que é possível registrar uma data e um local: final do século VII e início do século VI a. C, na cidade de Mileto - nas colônias gregas (Jônia) da Ásia Menor ${ }^{3}$.

Da mitologia à cosmologia, mobilizaram-se respostas às perguntas e problemas que surgiam dos eventos universais da natureza e de suas transformações. Em síntese, a filosofia surge quando:

se descobriu que a verdade do mundo e dos humanos não era algo secreto e misterioso, que precisasse ser revelado por divindades a alguns escolhidos, mas que, ao contrário, podia ser conhecida por todos, através da razão, que é a mesma em todos; quando se descobriu que tal conhecimento depende do uso correto da razão ou do pensamento e que, além da verdade poder ser conhecida por todos, podia, pelo mesmo motivo, ser ensinada ou transmitida a todos (Chauí, 1995, p.23).

Em obra intitulada $O$ que é a Filosofia?, Gilles Deleuze e Felix Guattari apresentam a questão do que é a Filosofia e, assim o fazem, lançando-a numa perspectiva radical e ao

\footnotetext{
3 Ainda que não seja nosso intento tratar dos períodos históricos da filosofia, tampouco ser nosso objeto de estudo, é valido tal registro já que é a partir deste momento que se introduziu uma maneira nova e original de se pensar a realidade e as transformações ocorridas na natureza e no homem.
} 
mesmo tempo pedagógica ${ }^{4}$ acerca do seu significado. Para tanto, preceituam que ela deve ser concebida como algo para além de sua dimensão conceitual.

A definição dada por estes amigos do saber ${ }^{5}$ acerca do que é conceito acabam por revesti-lo de uma qualidade pedagógica, na medida que o conceito envolve uma multiplicidade de acontecimentos que ainda estão por vir, e que não param de ser reinventados.

Isso significa que o conceito é capaz de criar uma dinâmica com o mundo, tornando os seres e as coisas comunicáveis entre si. Por isso, afirmam que o conceito é uma multiplicidade (Deleuze, Guattari, 1992, p.27). Em outra passagem, acentuam que ele é um ato do pensamento. (Deleuze, Guattari, 1992, p.33).

Sendo assim, o conceito se expressa como um ato do pensamento, e se remete à multiplicidade que se faz presente em torno dele. Como explicitam, "o conceito define-se pela inseparabilidade de um número finito de componentes heterogêneos percorridos por um ponto em sobrevoo absoluto, à velocidade infinita" (Deleuze, Guattari, 1992, p. 33).

Podemos entender que é através dos conceitos que se constroem mundos possíveis, dentro dos quais a convivência humana é sempre reconstruída, reinventada. Eis a força criativa do ser humano, enquanto ser potente construtor de mundos possíveis através dos conceitos. Ora, mas essa atividade seria restrita apenas e tão-somente aos filósofos? Como salientam Gilles Deleuze e Félix Guattari, a criação se manifesta por meio do conceito, sendo este o objeto próprio da filosofia, mas tanto a filosofia quanto o processo de criação do novo se esgotam nele?

Com base no significado exposto, depreende-se que o filósofo não possui o saber, mas busca o saber mediante o exercício prático da Filosofia, isto é, da "disciplina que consiste em criar conceitos". (Deleuze e Guattari, 1992, p.13).

Ainda quanto à originalidade do pensamento grego, começa-se a compreender o porquê "não haveria somente diferença de grau, como numa escala, entre o filósofo e o sábio:

\footnotetext{
${ }^{4}$ Os autores identificam três idades para o conceito: a saber, a enciclopédia, a pedagogia e a formação profissional comercial. Contudo, somente a segunda seria capaz de apreender o momento criativo da filosofia como momento singular da criação do novo. Este momento singular é um acontecimento que se desvela a partir da criação do conceito. Daí a criação do novo. È pedagógico porque está em permanente redimensionamento. Não é um estado de coisas, mas algo elástico. Conforme ponderam, "o conceito diz o acontecimento, não a essência ou a coisa" (p.33, Deleuze, Guattari).

${ }^{5}$ Mais adiante, o leitor poderá compreender nitidamente por que nos referimos nestes termos aos estudiosos Gilles Deleuze e Felix Guattari. Agora, deixamos essa abertura para que o próprio leitor faça sua conexão e interpretação face às explicações que se seguirão.
} 
velho sábio vindo Oriente pensa talvez por Figura, enquanto o filósofo inventa e pensa o conceito" (Deleuze e Guattari, 1992, p.11).

Feita esta breve apresentação sobre o significado e o aparecimento da filosofia, o que representa também um recorte ou divisor de águas na história da civilização Ocidental, passamos a analisar e a tentar entender o motivo pelo qual a experiência filosófica está ligada à formulação de conceitos.

Mais do que isso, como se poderá observar, seu objeto consiste em criar conceitos sempre novos (Deleuze e Guattari, 1992, p.13).

com efeito, é cediço que a prática filosófica guarda estreita relação com a produção de conceitos. por sua vez, o conceito revela-se como o produto ou o resultado da atividade do filósofo. em última instância, daí a filosofia ser entendida como a disciplina dos conceitos.

por outro lado, o que se quer demonstrar nessas linhas é que, não obstante a essa noção que liga a filosofia ao plano conceitual, ela é muito mais do que isso. o pássaro-filosofia necessita da outra "asa" ou "nadadeira". o conceito é apenas uma delas.

essas imagens bem que servem para ilustrar a impulsão que é a filosofia, obviamente, se considerada no seu duplo aspecto: conceito e plano. mas que plano é esse ao qual se referem os filósofos? eles mesmos respondem: "se a filosofia começa com a criação de conceitos, o plano de imanência deve ser considerado pré-filosófico" (Deleuze e Guattari, 1992, p.57).

convém advertir que nossa intenção aqui é analisar o que estaria por trás do plano conceitual da filosofia, do qual nos fala Deleuze e Guatarri, ou seja, desta dimensão no âmbito da qual nada está fora ou lhe é preexistente, mas a constitui enquanto impulso interno. ora, é a partir daí que será possível tratar da filosofia no sentido que buscamos enfatizar no presente trabalho, isto é, uma filosofia que "se endereça também, em sua essência, aos não-filósofos" (Deleuze e Guattari, 1992, pág.57).

feita essa observação, cabe esclarecimento importante quanto ao campo não-filosófico:

Ele está pressuposto, não da maneira pela qual um conceito pode remeter a outros, mas pela qual os conceitos remetem eles mesmos a uma compreensão nãoconceitual. Esta compreensão intuitiva varia ainda segundo a maneira pela qual o plano está traçado. (...) De qualquer maneira, a filosofia coloca como pré-filosófica, ou mesmo não-filosófica, a potência de um Uno-Todo como um deserto movente que os conceitos vêm a povoar. Pré-filosófica não significa nada que pré-exista, mas algo que não existe fora da filosofia, embora esta o suponha. São suas condições internas. O não-filosófico está mais no coração da filosofia do que a própria 
filosofia, e significa que a filosofia não pode contentar-se em ser compreendida somente de maneira filosófica ou conceitual, mas que ela se endereça também, em sua essência, aos não-filósofos (Deleuze e Guattari, 1992, p.57)

Revelam-se bastante esclarecedoras essas palavras, ou, antes, geram saudável inquietação, na medida em que explicam o que é a filosofia, remetendo tal questão a ela mesma, à própria filosofia, ao recolocarem a questão da filosofia como uma capacidade de criação que partirá dela mesma, do seu interior, pois aí reside, no seu âmago, toda criatividade. Eis o campo das sensações como condição de possibilidade para a criação do conceito, que é o ato do pensamento.

Já fica fácil perceber, nessas linhas iniciais, que, para eles, o mais importante ao tratar da questão do que é a filosofia consiste em não reduzi-la a mera construção de conceitos, mas compreender as condições que possibilitam o seu despertar, ou seja, os componentes intrínsecos que estão presentes no interior da filosofia e que conjugados resultam na criação de conceitos. Está aí uma maneira bastante original e peculiar através da qual demonstraram como a filosofia pode ser livre, alegre e viva.

$\mathrm{Na}$ esteira dessa reflexão crítica e, também, criativa por eles defendida repousa a possibilidade de que seja destinada tanto aos filósofos quanto aos não-filósofos. Eis o momento no qual o pássaro-filosofia pode alçar seu voo mais alto, ao agitar suas duas asas: o conceito e o plano de imanência ${ }^{6}$.

Vemos, assim, que a determinação de um conceito não passa de uma ressonância do que a filosofia é portadora no seu interior. É aqui, na sua parte interna, que a filosofia traz a sua chave-mestra além dos tempos e dos lugares. Aqui está sua potência para inventar conceitos, os quais se apresentam como um resultado da atividade filosófica.

De certa forma, o filósofo cria e recria conceitos, porém é preciso para o exercício dessa tarefa que se instaure um plano de imanência, sem o qual não há conceito, tampouco filosofia.

Para que o conceito ganhe vida, é preciso que tenha como ponto de partida a instauração do plano de imanência. Segundo os autores, essa se apresenta como a condição interna da filosofia e base de sustentação do próprio conceito.

Como registramos num primeiro momento, o conceito pode ser apresentado como um ato do pensamento. E, quanto a sua raiz, o plano de imanência, o que representa? Bem,

\footnotetext{
${ }^{6}$ Como advertem e ilustram nossos autores: “Ambos são necessários, criar conceitos e instaurar o plano, como duas asas ou duas nadadeiras" (Deleuze e Guattari, 1992, p.58).
} 
segundo os autores, o plano de imanência consiste na imagem do pensamento. (Deleuze e Guattari, 1992, p.53).

Neste sentido, devemos acentuar que a filosofia não pode ser entendida como uma atividade que resulta na mera formulação de conceitos, pois há um plano no seu interior que informa e torna toda criatividade presente no conceito possível. Ato do pensamento e imagem do pensamento são justamente essas duas partes necessárias da filosofia. Como nos lembram os autores,

o plano de imanência não é um conceito pensado nem pensável, mas a imagem do pensamento, a imagem que ele se dá do que significa pensar, fazer uso do pensamento, se orientar no pensamento (..) O pensamento reivindica "somente o movimento que pode ser levado ao infinito. O que o pensamento reivindica de direito, o que ele seleciona, é o movimento infinito ou o movimento infinito. É ele que constitui a imagem do pensamento (Deleuze e Guattari, 1992, p.53).

Essa intrigante observação feita pelos autores abre a possibilidade de verificarmos que, embora o conceito se apresente como a expressão concreta da atividade criativa do filósofo, existe um plano que serve de base para que possa efetuar sua territorialização, mas antes desterritorializando-se do plano. Seria uma condição interna sobre a qual o conceito deitaria suas raízes.

$\mathrm{Na}$ análise dos nossos "amigos do saber", podemos dizer que

A filosofia é, ao mesmo tempo, criação de conceito e instauração do plano. $O$ conceito é o começo da filosofia, mas o plano é a sua instauração. O plano não consiste evidentemente num programa, num projeto, num fim ou num meio; é um plano de imanência que constitui o solo absoluto da filosofia, sua Terra ou sua desterritorialização, sobre os quais ela cria seus conceitos. (Deleuze e Guattari, 1992, p.58)

Cabe observar que eles utilizam o artigo indeterminado "um" antes de "plano de imanência", o que significa que não estamos falando de um plano definido, como algo de natureza universal, ou princípio divino, nem natural, ou sequer sobrenatural. Ele é, na verdade, uma imagem que o pensamento faz dele mesmo, a partir do qual o filósofo se vale para fabricar seus conceitos. Assim, ainda que esteja na ordem do pensamento, o plano de imanência é remetido ao filósofo. Sua criatividade parte deste plano de imanência, o qual não está fora dele (filósofo), mas no seu interior. Com isso, "e porque o conceito deve ser criado que ele remete ao filósofo, como àquele que o tem em potência, ou que tem sua potência e sua competência" (Deleuze e Guatarri, 1992, p.13). 
Por conseguinte, seguindo as observações de G. Deleuze e F. Guattari, é possível distinguir os filósofos pela maneira com a qual cada um define seu plano de imanência.

Não é à toa que consideram Espinoza como o "príncipe dos filósofos", pois "ele encontrou a liberdade tão-somente na imanência. Ele acabou a filosofia, porque preencheu sua suposição pré-filosófica" (Deleuze e Guattari, 1992, p. 66).

$\mathrm{O}$ que devemos entender, precisamente, é que a atividade criativa da filosofia não se realiza de maneira individual. Como vimos, o conceito é multiplicidade. O plano de imanência é a imagem dessa multiplicidade. E que ambos se remetem ao filósofo. Logo, à medida que ampliamos o espectro dessa multiplicidade referente ao campo de imanência mais e mais as fronteiras do campo conceitual são postas à prova, passando por novos e atuais redimensionamentos.

Outro detalhe, Deleuze e Guattari vão colocar que "pensamento é criação, não vontade de verdade" (Deleuze e Guattari, 1992, p. 73). Ora, isso evidencia que está na base desse pensamento a capacidade de sentir o mundo a partir do plano de imanência. Por isso, se o filósofo é o amante da sabedoria, essa sabedoria é sempre registro de criação, e não de verdades prontas ou acabas. Daí que a tarefa do filósofo está ligada à ideia de criação e não de dizer verdades.

Convém mencionar também o que os autores entendem por outrem, haja vista que ele “surge neste caso como expressão de um possível” (Deleuze e Guattari, 1992, p.29). E é aqui que o campo de experiência do filósofo se amplia para além dele mesmo, explicando também a razão pela qual o conceito sempre traz o novo enquanto criação.

Outrem passa a ser uma realidade com a qual se pode preencher e construir o mundo da experiência com sentidos e significados, tendo em vista que "este mundo possível tem também uma realidade própria em si mesmo, enquanto possível” (Deleuze e Guattari, 1992, p.28).

Vale dizer que não haverá conceito sem que exista este outro o qual torna justamente o conceito possível. Ou melhor, sendo outrem a expressão de um mundo possível, o conceito exige essa intermediação com outrem, já que nele se torna uma extensão e expressão daquilo que se criou. Por outro lado, é campo de imanência que empolga todas as capacidades criativas do conceito.

Retomando o que já foi dito até aqui, o filósofo pode ser visto como aquele que tem amor e respeito pela sabedoria. Cônscio de que não sabe, não possui o saber, ele então se lança na tentativa de entender o porquê das coisas, dos acontecimentos, dos eventos, das 
condutas, das ações, enfim, do mundo humano e natural que o cerca. Para tanto, ao perseguir essa tarefa, ele vai atribuindo significados ao mundo e as coisas, ou seja, conceituando o que se lhe apresenta diante de seu campo perceptivo ${ }^{7}$. Assim, a essa imagem que se tem deste todo circundante se chama plano de imanência. Com outras palavras, o plano de imanência revelase como uma sensível capacidade de percepção do mundo, atenuando ou acentuando o que vai se expressar em ato, ou como agora podemos entender, o conceito. Sentir para pensar, criar uma imagem do pensamento, e pensar para criar, projetar um mundo possível, uma miríade de alternativas, eis aí a bela atividade do filósofo. É quando ele diz "não" a este mundo do conformismo, criando alternativas vivas e ativas para vida em sociedade. É quando ele diz "não" ao conceito de pobreza global, ao criar conceitos para rebater esta ideia segundo a qual tal mazela humana está além do alcance dos governos, quando na verdade existem países que sequer conhecem a fome ou a falta de educação como realidades suas. Pensar é criar, mas sentir é a base e a condição fundamental para ambos. A capacidade perceptiva e sensitiva da vida amplia nossos horizontes de tal monta que somos capazes de estender as mãos na solidão, superarmos com solidariedade a pobreza e desigualdade, ensinarmos a concórdia diante da guerra, dar exemplo de gratidão quando houver prepotência, compartilhar quando pretende-se dividir, levar alegria onde houver tristeza, permeados que somos pelo amor, enfim, superar tudo aquilo que em nós pode nos tornar menores em nós mesmos. Neste passo, sentir passa a ser não uma medida, mas uma potência constitutiva do eu com o outro, ou seja, o caminho de nossa própria libertação. Isso explica bastante, inclusive, a natureza pedagógica que deve ser reconhecida à filosofia, de acordo com o que foi acima exposto, a partir do pensar como o outro.

Com estas palavras, sedimentamos um terreno teórico para entender adequadamente o que é a "Não Filosofia", enquanto objeto deste segundo capítulo, e parte integrante do estudo de nosso trabalho.

Se a filosofia é a criação de conceitos, a Não Filosofia é a sensação dos mesmos. A primeira é a aparência, enquanto a segunda a essência.

Analisando a seguinte passagem, "assim, pois, a questão da filosofia é o ponto singular onde o conceito e a criação se remetem um ao outro" (Deleuze e Guattari, 1992, p.20),

\footnotetext{
${ }^{7}$ Conforme veremos no capítulo referente à Estética, o homem em contato com a natureza constrói valores e significados, tornando esse mundo não mais natural, mas cultural. Logo, criação. Somos capazes de perceber e sentir as criações humanas e repassá-las adiante através desse mundo cultural. Assim, a criação parte de um sentir, informando ao pensamento as capacidades infinitas de projeção da realidade. Quanto mais sensíveis formos, mais sentires, e daí mais possibilidades constituídas em ato pelo pensamento.
} 
compreendemos que tanto o conceito quanto a criação são uma só e única realidade, já que assumem este lugar singular.

A singularidade pode ser entendida enquanto tudo aquilo que existe em si, na medida mesma em que se diferencia do todo.

Assim, é na sua relação com outras realidades conceituais que se define um conceito enquanto realidade filosófica. Entender isto importa dizer que é compreendendo que existem outros que é possível se criar algo diferente, singular, potente em si. Ou seja, é através da sensação, essa condição interna da filosofia, que se torna possível recriar conceitos sempre novos. Caso contrário, ter-se-iam conceitos, atos de pensamento, sempre iguais, sempre prostrados ou tolhidos na fonte de sua inventividade, plano de imanência. Graças à sensação somos sempre novos e inventivos. Por seu turno, esta capacidade não está limitada aos filósofos. Desde que se tenha a capacidade para sentir, é possível a criação, isto é, a invenção de conceitos.

Como podemos perceber a filosofia é caracterizada pela relação com o pensar, mas também com o conhecer, agir e o sentir, nas palavras do filósofo Elton Luiz Leite de Souza (2007, p.25)

Quem se permite sentir, abre-se a possibilidade para criar, podendo efetivamente dar seu voo filosófico. Conceito e plano de imanência. Ora, se sentir é a condição para o pensar, a filosofia concerne a todos, ou seja, ao campo das sensações, e todos nós podemos sentir e projetar mundo possíveis.

\title{
4. DO NÃO DIREITO: O AMOR COMO FUNDAMENTO ORIGINAL DO DIREITO
}

\author{
"quando o saber junta-se com o saber que não sabe então \\ a ciência converte-se em poesia" \\ (Francesco Carnelutti)
}

Em “A Arte do Direito”, Francesco Carnelutti procura demonstrar a relação que há entre a arte e o direito. Ele nos faz perceber que existe um campo singular pertencente tanto ao estudo do fenômeno do direito e seus conceitos quanto ao estudo dos conceitos e o fenômeno da arte. Eis aí nosso intuito: o desejo de saber sobre esta relação, seu ponto de interseção, seu entroncamento, seu ponto comum. Isso fica mais claro, ao se realizar a leitura da passagem seguinte:

Finalmente adverti que estudar o direito e a arte significa atacar a partir dos dois lados diversos o mesmo problema. Por desconcertante que seja esta afirmação, 
chegou para mim o momento de fazê-lo. O mesmo problema, digo, conforme o perfil da função e da estrutura (2005, p. 10).

Ao fazer esta aproximação do direito com a arte, ele vai afirmar que "a arte, como o direito, serve para ordenar o mundo. O direito, como a arte, tem uma ponte do passado para o futuro" (Carnelutti, 2005, p.10). Sendo assim, ambos estariam estruturados de modo a perseguir sua função de ordenação do mundo. Função essa que é desenvolvida através da adivinhação, a qual pode ser considerada como o grande segredo tanto da arte quanto do direito.

Para ele, a "dificuldade e a nobreza, o tormento e o consolo do direito, como da arte, não podem representar-se melhor do que com essa palavra! Adivinhar indica a necessidade e a impossibilidade do homem ver o que vê somente Deus" (Carnelutti, 2005, p. 10).

Nesta obra, no capítulo que trata especificamente do que é o direito, Carnelutti observa que deveria se socorrer de um artifício, a comparação. Nessa linha, partindo de um primeiro exercício comparativo, ele dirá que "o conceito de direito liga-se estreitamente ao conceito de Estado" (Carnelutti, 2005, p.14).

Em função disso, bastaria conhecer o conceito de Estado para se alcançar a resposta do que é o direito. Com outras palavras, antes de responder ou ter a pretensão de responder o que é o direito, seria necessário encontrar um conceito mais transparente e mais próximo do conceito de direito, tal como se revela o conceito de Estado. E o que é Estado? nas suas palavras, "o verbo latino stare é o que se vê através do cristal; e com isso transparece a ideia de firmeza, do que aí está" (Carnelutti, 2005, p.14).

Num sentido geral, o Estado pode ser representado como a configuração política de uma dada comunidade. Daí que "o povo, enquanto alcança certa firmeza, converte-se em Estado" (Carnelutti, 2005, p.14). Desde já, a ideia que deve ficar nítida é a seguinte: o Estado representa um conjunto unitário no qual estão contidos todos os indivíduos de uma mesma comunidade.

Ora, e o direito? Onde estaria? Aqui cabe o segundo exercício comparativo. Para Francesco Carnelutti, a mesma diferença existente entre os tijolos e o arco de uma ponte, haveria também entre povo e Estado. Assim, quando de longe avistamos uma ponte, poderíamos considerá-la a representação simbólica do Estado. E para cada tijolinho daquele, unido à estrutura do arco, seria um elemento do povo. Eis que a força que operaria na união de cada tijolo usado para a construção do arco da ponte e mantê-la firme, encontrar-se-ia transfigurado exatamente o direito, ou melhor, a força do direito. 
A partir daí, temos que os tijolos são os homens do povo, o qual encontra-se firme e estável no arco, que é justamente o Estado. Porém, para alcançar esta estabilidade, é preciso uma armação que ofereça sustentação até que todo o arco da ponte se complete. É justamente em função dessa necessidade que o direito atua.

Enquanto força associativa, ele une e vincula cada elemento de modo a transformá-lo num todo. Isso é o que podemos compreender a partir das lições do autor:

Estado é verdadeiramente um arco (...) Há, sem dúvida, uma força que mantém os tijolos unidos ao arco (...) sem armação o arco pode resistir depois de terminado; mas, antes, sem armação, não se sustentará, o arco seria lançado à terra. O direito é a armação do Estado. O direito é o que o povo precisa para que o povo possa alcançar a sua estabilidade (2005, p. 14).

Em outra passagem, pode-se perceber esta função unificadora exercida pelo direito da qual nos fala o autor: "O ius une os homens como o iugum liga aos bois e como a armação aos tijolos"(Carnelutti, 2005, p.15).

E, mais adiante, para concluir, o autor vai identificar que efetivamente na palavra direito está contida a ideia do vínculo, o que o leva a outra comparação: "não é a reta a linha que une dois pontos? Os pontos são os homens que formam o povo, e a linha, precisamente, o vínculo eu os mantém unidos em um só conjunto"( Carnelutti, 2005, p.15).

Tudo resolvido? Não. Se desejamos encontrar realmente o manancial donde provêm tanto o direito quanto a arte é vital proferirmos o nosso Não. E, assim, chegara o momento da aurora, de entendermos o que significa Não Direito.

Embora reconheça a importância do direito, o autor se opõe à perenidade do mesmo e sua proximidade da noção de Estado. Como vai sinalizar, " aqui está minha dúvida; mais bem e sinceramente, minha oposição. Eu creio na eternidade do Estado ou, mais exatamente, na duração do Estado até o fim do mundo; mas Estado e direito não são o mesmo, ao menos se esta última palavra é tomada em seu significado mais amplo e puro"(Carnelutti, 2005, pág.15).

Primeira pergunta: enfrentando a questão da duração do direito, quando o arco da ponte se completar, a armação que lhe conferia sustentação continuaria a existir? Haveria duração para a permanência do direito? E o antigo aforismo romano ubi societas ibi ius?

Segunda pergunta: Que Estado é esse sem direito? O que permearia as relações entre os indivíduos?

Terceira pergunta: O que corresponderia esse direito amplo e puro? Que força? 
Para Francesco Carnelutti, a vigência do direito é uma questão de necessidade. Isto porque, ao se analisar a célula familiar, enquanto forma original do Estado, pode-se entender bem que há grupos e conjuntos socais que prescindem do direito. Como acontecia com as famílias romanas cujo pater famílias consistia em seu o estatuto jurídico, ao passo que nas famílias de base religiosa cristã, caracterizadas pela ausência do direito, os relacionamentos estavam ligados por uma outra força de integração.

Com efeito, analisando-se a semente do fenômeno estatal, a formação familiar pode ou não contar com a presença do direito. $\mathrm{O}$ autor faz questão de afirmar "os arcos sem armação são raros ainda; mas o pensador observa com atenção e com maravilha vendo neles o princípio do Estado na sua pureza" (Carnelutti, 2005, p.17).

Conforme advertência feita pelo próprio autor, "no Estado de direito não podemos ver, pois, a forma perfeita de Estado. Os juristas são vítimas, neste ponto, de uma incrível ilusão"(Carnelutti, 2005, p.19).

Como podemos constatar, há uma cegueira que não nos deixa ver o que levamos de humanidade dentro de nós. De acordo com Hanna Arendt, "cada homem é singular, de sorte que, a cada nascimento, vem ao mundo algo singularmente novo" (Arendt, 1987, p.191).

Todo esforço em conquistar esta lente que nos permita ver o que portamos dentro de nós mesmos traz uma recompensa: Liberdade. O verdadeiro direito é aquele que se coloca como uma extensão do outro, e não restringindo-o ou esquecendo-o, como acontece na vida dos dias atuais.

Direito potente é direito livre, o que coloca em xeque aquela velha noção de que " meu direito começa quando outro termina" (Cunha, 1998, p.51).

É disso que nos fala o jurista Francesco Carnelutti, ao enfatizar que "o bem de um e de outro é o bem da mesmo pessoa"(Carnelutti, 2005, p.18).

Portanto, outrem é extensão do meu direito e de minha liberdade, justamente porque o bem de ambos é o outro. Permita-nos a afirmar que não pode haver direito maior do que este. Por conseguinte, o bem verdadeiro pode ser chamado de liberdade. E esta não precisa do direito, vez que "um homem obrigado é um homem amarrado, e um homem amarrado não tem liberdade"(carnelutti, 2005, p20). Mas como chegar a ela? Através do direito?

De acordo com Francesco Carnelutti, "uma força é o direito, mas não a força original. Ao contrario, uma força secundária”( Carnelutti, 2005, p.20). Se não é através do direito que atingimos aquele bem, liberdade, pois trata-se de uma força secundária, cabe indagar que força original nos conduziria ao Bem? Responde-nos o autor: O Amor. É ele essa força 
original presente no interior do próprio direito. Com outras palavras, ainda que o direito represente essa ideia de ligação ou união, é o amor que contem a forma mais pura de ligação, "uma força interior une os homens e faz de uma multidão uma unidade"(Carnelutti, 2005, p.18).

Neste momento, já podemos falar sobre o que significa Não Direito, justamente porque ficou claro que o direito apresenta-se como algo superficial ou secundário.

Em linhas gerais, o verdadeiro direito está no seu interior. Enquanto força original, é a única força capaz de unir a liberdade dos homens e fazer de uma multidão de singularidades uma unidade. É assim uma força socializadora e integrativa, e não restritiva.

Por outro lado, é necessário ressaltar que ainda é necessária a presença do direito "enquanto os homens que não saibam amar necessitam de juiz e policiais civis para mantê-los unidos. Quer dizer: enquanto os homens não saibam amar temos que obrigá-los" (Carnelutti, 2005, p. 20).

Contudo, o autor se esforça em nos lembrar que o direito é uma força, dunamis, como diziam os gregos. É essa força que liga e que ordena. Na medida em que "força não significa mais do que a idoneidade de algo para transformar o mundo" (Carnelutti, 2005, p. 19), a fonte do direito consiste justamente nessa idoneidade para ordenação e transformação do mundo, o que nos aproxima da arte, conforme foi dito acima.

Embora a alguns possa parecer utópico o posicionamento do ilustre jurista italiano acerca da natureza do direito, é importante registrar que não foi nossa intenção, em nenhum momento, enfrentar a discussão sobre a eternidade do direito, tampouco defender a ideia de que estaria próximo o momento de vencer a etapa do Estado jurídico, passando-se àquele puro e estável, mas sim verificar o que o autor chamou de força originária do direito, Não Direito, capaz de constituir um Estado alicerçado pela força do Amor e do encontro das liberdades humanas, no seu sentido mais pleno. Não há como negar que essa força exista, evidentemente. Contudo, reconhecemos sua manifestação quer limitada quer apenas em estado latente. Como encontrar sua manifestação plena? Como verificá-la na prática? Eis a saída oferecida pelo autor, e sustentada por nós, através da Arte.

Portanto, a compreensão acerca do Direito renasce a partir de um ponto de vista completamente novo, geneticamente reinventado, humanamente preenchido, esteticamente expressivo, vez que

"como todo fenômeno cultural, o direito necessita de meios corpóreos de expressão: da linguagem, dos gestos, do traje, dos símbolos e edifícios. Como qualquer outro 
meio, também a expressão corpórea do direito está submetida à avaliação estética. E como todo fenômeno, o direito pode penetrar no domínio específico da valoração estética como matéria da arte. Exige-se, portanto, uma estética do direito" (Radbruch, 2010, p. 156).

Conseguimos vislumbrar, em alguma medida, que "pensar como o direito pode se articular com a arte para a humanização das relações sociais" (Bittar; Almeida, 2015, 779) implica considerar a máxima romana "ubi societas ibi ius" para além do traço normativo, ou seja, o direito como expressão da própria sociedade, constituindo aí as bases da estética do direito.

Pensar a relação Direito e Não Direito nos aproxima das lições de Radbruch ao dizer que

\begin{abstract}
“Desse modo cumprimos a passagem da expressão artística do direito, ao direito enquanto matéria da arte. A propriedade que torna o direito uma matéria sedutora da arte é a multiplicidade de antíteses que lhe é intrínseca, a oposição entre ser e dever ser, entre direito positivo e natural, direito legítimo e direito revolucionário, entre liberdade e ordem, justiça e equidade, direito e graça etc.” (Radbruch, 2010, p. 159).
\end{abstract}

Percorremos o caminho da Não Filosofia. Em seguida, fizemos o mesmo mapeamento no direito, reconhecendo a existência de uma outra força para além da obrigação jurídica. Com outras palavras, orientados pelas lições de Francesco Carnelutti, fizemos notar que existe uma força primeira ou original cuja capacidade para ligar e unir os homens põe de lado o império da lei (força de sustentação), tendo em vista que, ao contrário desta, aquela funcionaria como força fundante de organização da sociedade.

Sendo assim, certos estamos que chegara o momento de precisar a fonte comum de ambas abordagens, quando se pode estabelecer um plano de imanência na filosofia, bem como reconhecer uma fonte original de coesão social no direito, restando-nos cumprir com a pesquisa acerca do que representa esse campo das sensações.

De plano, ao tratarmos de campo das sensações, quase que despercebida e intuitivamente, somos tentados a formar uma conclusão, qual seja, falar sobre sensações é falar sobre sensibilidade, a qual encontra-se presente quer no direito quer na filosofia.

E, uma vez imersos no mundo da sensibilidade, indagamos: o que nos trouxe até aqui? O Direito ? A Filosofia ? Como? Trata-se de utopia, pois não podemos ver? Não recairíamos no mesmo problema apontado por Carnelutti, quando diz que os juristas vivem em plena ilusão, vez que se contentam com esta forma jurídica de Estado? 
$\mathrm{Na}$ verdade, estamos no campo das artes, e aqui muito mais do que ter razão, o que vale mesmo é sentir.

Chegamos, enfim, no universo da arte, guiados que fomos pela nossa sensibilidade, em torno de questões centrais do direito e da filosofia, o que nos leva a concluir que o campo das sensações é um campo aberto e comum entre a filosofia e o direito, ressignificando o estudo acerca de ambos.

\section{CONCLUSÃO}

Eis o nosso trabalho, pesquisou-se, criou-se. À aparência acabada e pronta, as ideias que ficaram da sua leitura já reivindicam novos traçados, empolgando novos debates e novos caminhos a serem percorridos, como uma forma de abastecer o desejo de saber, cônscios de que portadores apenas e tão somente da sensibilidade. Daí amigos e amantes do saber, porque desejosos eternos do saber a partir de nosso sentir, através da percepção e afetividade, o mundo à nossa volta.

Procuramos demonstrar que o campo das sensações consiste num espaço sempre aberto, imanente, onde não há nada fora, sendo capaz de provocar a inventividade dos conceitos, bem como a radicalidade do direito como instrumento de construção, ordenação e unificação humana.

As linhas foram traçadas, não se sabe se iniciais, intermediárias ou finais, mas encontram-se estendidas como uma mão, convidando o nobre leitor a conhecer um pouco do campo das sensações tanto no direito quanto na filosofia.

O horizonte se perde numa miríade de possibilidades, as quais configuram-se como terrenos férteis para novos frutos.

Da Não Filosofia ao Não Direito descobrimos que há algo mais profundo no ser humano do que ele em si, revelando a possibilidade de se ultrapassar qualquer determinação transcendente que se queira impor.

Por fim, buscou-se falar do campo das sensações no direito e na filosofia, entendendo que ele nada mais é do que uma capacidade inerente a todos os seres humanos enquanto potencialidade de criação de mundos possíveis com o outro, ou seja, expressão do sentir. Por conseguinte, apresenta-se como fundamento para se pensar o direito como fruto da criação humana, como expressão da ordenação da vida social, como arte. Se é pela vida que o indivíduo constrói a realidade concreta, essa construção não acontece por si só, mas com os demais membros da sociedade, com os outros. Assim, acreditamos que o valor maior que poderá ser erigido entre os seres humanos deverá ser aquele que expresse a pluralidade e 
multiplicidade da realidade humana. Com outras palavras, o direito é, por essência, coletivo, plural e emancipador em um caminho inacabável.

\section{REFERÊNCIAS}

ARENDT, Hannah. A Condição Humana. 2.ed. Rio de Janeiro: Forense-universitária,1987.

BITTAR, Eduardo Carlos Bianca; ALMEIDA, Guilherme Assis de. Curso de Filosofia do Direito. São Paulo: Editora Atlas S.A, 2015.

CARNELUTTI, Francisco. A Arte do direito. $4^{\mathrm{a}} \mathrm{ed}$. SPCampinas: Bookseller, 2005.

CHAUÍ, Marilena. Convite à Filosofia. 5.ed. São Paulo: Ática, 1995.

Introdução à História da Filosofia: dos Pré-Socráticos a Aristóteles. 1.ed. São Paulo: Brasiliense, v.1, 1994.

O que é a Filosofia?. 1.ed.Rio de Janeiro: Ed. 34, 1992

CUNHA, José Ricardo Ferreira. Direito e Estética - fundamentos para um direito humanístico. 1.ed. Porto Alegre: Sergio Antonio Fabris editor, 1998.

DELEUZE, Gilles; Guattari, Felix. O que é filosofia? 2.ed. Rio de Janeiro: Ed. 34, 1992.

FABRIZ, Daury César. A estética do direito. 1.ed. Belo Horizonte: Del Rey, 1999.

HUISMAN, Denis. A Estética. 1.ed. São Paulo: coleção“ Saber Atual”, 1955.

LISPECTOR, Clarice. A descoberta do mundo. Rio de Janeiro: Rocco, 1999.

RADBRUCH, Gustav. Filosofia do Direito. $2^{\mathrm{a}}$ ed. São Paulo: Editora WMF Martins Fontes, 2010.

SOUZA, Elton Luiz Leite de. Filosofia do Direito, Ética e Justiça: filosofia contemporânea. Porto Alegre: Núria Fabris Ed., 2007.

Manoel de Barros: a poética do deslimite. Rio de Janeiro: 7Letras, 2010. 